\title{
AN ANALYSIS OF WEST COUNTRY DIALECT USED BY HAGRID IN J.K. ROWLING'S HARRY POTTER
}

\author{
Rika Santika \\ riksantika@gmail.com \\ LIA Gayungsari Surabaya
}

\begin{abstract}
English, like other languages, owns distinctive varieties which enrich the language itself. Dialect is one of the interesting topics which grabs linguists' attention to analyze. This paper analyzes one of the English dialect, called West Country, in a novel entitled Harry Potter and The Sorcerer's Stone by J.K. Rowling. Hagrid, a gatekeeper of Hogwarts School uses unique utterances which differ from other characters' utterances in the novel. The writer employed descriptive research since the analysis is about discussing, analyzing, and finding the dialect patterns. The data of this study are taken from one of the novels in Harry Potter and The Sorcerer's Stone. The three important features which were found in the dialect varied in terms of the phonology features, the grammatical pattern, and the vocabulary variation. This study shows that Rowling attributes the dialect to Hagrid for a reason that people from West Country are very simple and humble.
\end{abstract}

Keywords:language variation; dialect; West Country; Hagrid.

\section{INTRODUCTION}

Dialect is a variety of a language associated with a particular group of speakers and mutually intelligible with other varieties (Wardhaugh, 1977:221). In this case, mutually intelligible means that "the speakers of one variety can understand the speakers of the other and vice versa" (Schilling-Estes, 2006:313). According to this definition, she provides an example that "different varieties of Chinese (e.g. Cantonese and Mandarin) are linguistically quite different from one another and are not mutually intelligible (at least in spoken form), and yet speakers of these varieties typically consider themselves to be speakers of a single language, Chinese" (ibid).

The previous dialectal study shows that the use of dialect represents the social background of the users who are often regarded as people who think less about the language variation they use since the dialect was already attached to them. Moreover, the use of the dialect represents the intention of the users to get more intimate and show regional loyalty to the hearers. This case considers that dialectal research helps people to understand the language variation used by few people in order to grab the whole intended meaning.

\section{REVIEW OF LITERATURE}

Mugglestone (2006:311) pointed out the three essential dimensions of dialect variation which may be observed among dialects as they provide a useful structure for the detailing of 
dialectal features. These types can show the social class where the person belongs to. First is the Phonology Features. The differences among dialects could lie in the distinctive phonology features. Moreover, Wardhaugh (1977:221) states that the existence of the differences invested in vowels and consonants of "a particular region and the phonetic values of the phonemic contrasts" have been investigated by linguists.

Second is Grammatical Pattern. Wardhaugh (1977:221) states that grammatical differences among dialects are largely morphological in nature. The variation is not only found in the morphological case, but also can be found in the use of past and present tense verb form (Holmes, 1992:160). Furthermore, negative forms and the use of "ain't" also hold a variation among dialects usually by the use of multiple negations. The use of those distinctive grammatical patterns indicates lower social class because people in the middle and upper class often avoid using those vernacular forms of grammar.

Western Counties in England has distinctive features in grammatical pattern as has been mentioned out by Marshall (1789) in Burchfield (1994). He points out in a section entitled Provincialism of the Vale of Gloucester "the use of accusative forms of pronouns,..., the use of he instead of it, and the reduced form of the third person singular pronoun,..,,together with the voicing of initial fricatives, are common to the western counties in general" (Burchfield, 1994:209). In addition to it, Halliwell (1881) also in Burchfield (1994:212) shows that "Worcestershire, Warwickshire, and Gloucestershire also share pronoun exchange (as in Her's going for a walk with she), which definitely suggests a south-western rather than a northern connection".

Third is Vocabulary Variation. Many pairs of words distinguish the speech of the upper class from the rest. For example, Holmes (1992:149) provides an example in England in the 1950s which shows that the use of 'sitting room' (upper-class speaker) is different from 'lounge' (the rest).

Studies on the topic of dialect have also been conducted. Bucholtz et al. (2007) and Abdul A'la (2009) did studies which show that the use of dialect can describe the purpose and distinguish the person. A certain dialect might be used to attain a specific goal. Hometown dialect may be used to gain intimate relationship as the people share the mutual background. Moreover, it can be used to show the identity of the user. Therefore, the present study aims to reveal the pattern of the West Country dialect and the significance of the dialect toward Hagrid's characteristics. 


\section{RESEARCH METHODS}

In conducting this research, the writer uses the descriptive research. Descriptive approach is taken as the analysis is about discussing, analyzing, and finding the dialect patterns. The data of this study are taken from one of the novels in Harry Potter series written by J.K. Rowling entitled Harry Potter and the Sorcerer's Stone. The data of this study are the words, sentences, utterances, or expressions produced by Rubeus Hagrid and others related to Hagrid's speeches.

In collecting the data, the writer, firstly, reads Harry Potter and the Sorcerer's Stone novel thoroughly. The next is finding the words, sentences, utterances, or expressions uttered by Hagrid and other character related to Hagrid as supportive data. Then, the writer categorizes the words, sentences, utterances, or expressions produced by Hagrid into the standard and non-standard form. Later, the writer looks at the form and the meaning of the words which are used differently compared to other characters and the Standard English, by considering the context. Finally, the writer groups them into several classifications to the three types of dialect variation.

\section{RESULTS AND DISCUSSIONS}

\subsection{Dialect Pattern used by Hagrid}

Rubeus Hagrid is a gatekeeper of Hogwarts School of Witchcraft and Wizardry. He is very distinguishable through the way he speaks. The dialect is a part of England dialects because Rowling is from England. Therefore, the environment influences her to write based on her surroundings. There are three types of variation that distinguish one dialect with another. They are the phonology features, grammatical pattern, and vocabulary variation.

\subsubsection{Phonology Feature}

\section{[t] dropping}

The [t] dropping is accumulated in some words. Firstly, we are going to focus at the $[\mathrm{t}]$ dropping which is presented in three words; 'just', 'first', and 'last', which are uttered by Hagrid:

- “Now wait jus' one second!” (49)

- “any more firs' years?” (111)

- “bought him off a Greek chappie I met in the pub las' year - " (192)

The italicized and bold words are typed differently. They are typed only 'jus', 'firs', 'las"' as the consonant $[t]$ is dropped. The sentences contain some other words which end with [t] such as 'wait', 'bought', and 'met'. However, Hagrid only drops the final consonant of [t] at the aforementioned three words; 'just', 'first', and 'last'. This relies on the principle of ease 
of articulation. The principle covers the simplest way to pronounce words and eases the speaker in producing words. Hagrid tends to simplify the words whose pronunciation of the last $[\mathrm{t}]$ consonant comes after another consonant. They are:

$>$ Just: /jəst/

$>$ First: /fə : st/

$>$ Last: /la : st/

Those words are commonly pronounced with $[\mathrm{t}]$ as the final phone. However, Hagrid drops the $[\mathrm{t}]$ so the last $[\mathrm{t}]$ phone remains unpronounced. It is due to the existence of another consonant which is prior to the $[\mathrm{t}]$ phone. From those three words, there is a pattern of which word Hagrid simplifies. All of the last $[\mathrm{t}]$ phones come after $[\mathrm{s}]$ consonants. By taking the principle of the ease of articulation, it can be concluded that Hagrid finds the need to simplify the last [t] while there is another consonant, in this case is [s] consonant, which exists before it. Nevertheless, the pattern only applies in the three aforesaid words because there is another word in Hagrid's dialogs which is also ended with [t] consonant that comes after [s] consonant but does not receive same treatment of [t] dropping. The word is 'must'. There is a word whose last [t] phone is dropped despite the existence of a vowel prior to it. The word exists in the following dialogs:

- “... but I never thought yeh wouldn't even know abou' Hogwarts, fer cryin’ out loud!”(49)

The word is commonly pronounced /a'baut/ but Hagrid pronounces 'abou', as he drops the last [t] phone. However, the [t] dropping is only applied only on 'about', not to other words whose last $[\mathrm{t}]$ phones come after a vowel.

Besides dropping the last consonant of [t] of some words, Hagrid also drops the last $[\mathrm{t}]$ consonant in the contraction of negative words.

- "he wouldn' take his cloak off." (265)

- “Mighta bin a dragon dealer, mightn' he?" (265)

All dialogs above contain contractions of negation. Hagrid omits the last [ $\mathrm{t}$ ] consonant of the italicized and bold words. Other contractions which are pronounced differently are 'don', 'aren', and 'wasn'”.

However, there are special circumstances where Hagrid uses standard form. The tensed circumstances make Hagrid have the urge to use a correct pronunciation as he does not drop the last $[\mathrm{t}$ ] phone. It is due to the fact that people tend to use standard form in certain circumstances in purpose of becoming more firm and being able to grab attention, for example when he is in rage toward The Dursleys family. The dialog is below: 
- “- knows nothin' abou’-about ANYTHING?” (49)

If the former 'about' is pronounced dialectally, the latter 'about' is pronounced in standard form. The situation where the dialog produced is very serious as The Dursleys keep provocatively trying to stop Hagrid bringing Harry to Hogwarts, School of Witchcraft and Wizardry.

However, Hagrid shows an inconsistency of how he speaks especially in using the dialectal features. There are normal circumstances but Hagrid uses standard form. It will be revealed throughout the analysis.

\section{[d] dropping}

There is only one word whose last [d] phone is dropped. The word is 'and' as shown in the following dialogs:

- “Lily an' James dead — an' poor little Harry off her live with Muggles —”' (14)

- “An' like I told yeh, I'm Keeper of Keys at Hogwarts- " (49)

However, there are also special circumstances that cause the different pattern as shown in the following dialogs:

- "He's off ter the finest school of witchcraft and wizardry in the world. Seven years there and he won't know himself." (58)

In this situation, Hagrid is stressed out with the fact that Harry does not know anything about his magical background because The Dursleys keep it as secret from Harry. Hagrid seems to lose his temper and tend to use standard form as his need to be listened well and to take The Dursleys' attention.

\section{[v] dropping}

Like the [d] dropping feature, this consonant dropping is also accumulated only in one word.

- “yeh'll know all about Hogwarts,o' course." (49)

- "A wizard, o’ course," (50)

Hagrid drops the $[\mathrm{v}]$ phone of the word 'of' to be only 'o'. Uniquely, there is a word similar to 'of' which ends in almost similar consonant but is pronounced correctly. The word is 'off' as shown in the following dialogs:

- “an' poor little Harry off ter live with Muggles _ ” (15)

The pronunciation of word 'off' is similar to word 'of'. The word 'of' is commonly pronounced as /ov/ with strong form /av/. Meanwhile, the word 'off' is commonly pronounced as /af/. Both of the last consonant of [v] and [f] are pronounced in labiodentals part. The difference between them only lies on whether it is voice or voiceless. The [v] phone 
is voiced, while the [f] phone is voiceless (Rowe, 2012, 76). Voiced and voiceless spirants show different phonological properties (Gussmann, 2002, 16). With the principle of the ease of articulation, a voiced phone is rather more difficult to pronounce compared to the voiceless one.

\section{-in ending}

The -in pronunciation is also featured in Hagrid's dialogs which represent the distinctive dialect. It is by simplifying the pronunciation of the -ing form of a verb. (verb+-ing) and words ended by -ing.

Firstly, the most common -in ending appears in the -ing form of a verb as shown below:

- 'but I got him out all right before the Muggles started swarmin' around. He fell asleep as we was flyin' over Bristol." (15)

- "or maybe he just liked killin' by then. (55)

The -ing ending also appears in words ended with -ing such as 'nothing', 'everything', 'anything', and 'something'. The words become 'nothin', 'everythin', 'anythin', and 'somethin',

Yet, there is an inconsistency of using the -in ending in one of Hagrid's dialogs as shown below:

- "Dunno what Harry thinks he's doing," (189)

Here, Hagrid uses a dialectal feature of contracting the pronunciation 'dunno' which will be explained later but pronounces 'doing' in a standard form. There is a significant inconsistency as what has been revealed in the previous point where Hagrid uses standard form in a normal circumstance. Inconsistency also appears when Hagrid juxtaposes dialectal feature with standard form in one sentence.

\section{Contracting the Pronunciation}

Hagrid maximizes the principle of the ease of articulation in producing speech. $\mathrm{He}$ simplifies some words by contracting them into a non-standard form. However, the contracted pronunciation still maintains to have a similar pronunciation to the standard one. Here the table of some of Hagrid's contracted pronunciations:

Table 1. Contracted Pronunciation by Hagrid

\begin{tabular}{cc}
\hline $\begin{array}{c}\text { Contracted } \\
\text { Pronunciations }\end{array}$ & Standard Pronunciations \\
\hline summat & somewhat \\
myst'ry & mystery \\
'course & of course \\
'em & them \\
outta & out of \\
shouldn'ta & shouldn't have \\
\hline
\end{tabular}




\begin{tabular}{cc}
\hline 'cept & except \\
s'pposed & supposed \\
sorta & sort of \\
\hline
\end{tabular}

\section{Distinctive Function Words Pronunciation}

One prominent point of the dialect is the distinctive pronunciation of the function words. Hagrid pronounces the words of 'to', 'you', 'your', and 'for' differently as shown below:

- “an' poor little Harry off ter live with Muggles - " (15)

- 'I knew $\boldsymbol{y} \boldsymbol{e h}$ weren't gettin' $\boldsymbol{y} \boldsymbol{e r}$ letters but I never thought $\boldsymbol{y} \boldsymbol{e h}$ wouldn't evenknow abou' Hogwarts, fer cryin' out loud!” (49)

Table 2 Hagrid's Distinctive Function Words

\begin{tabular}{cc}
\hline Function Words & Dialectal Features \\
\hline to & ter \\
you & yeh \\
your & yer \\
for & fer \\
\hline
\end{tabular}

There is also a special circumstance where Hagrid uses standard form instead when he is angry to the Dursley family and has the urge to get more attention.

\subsubsection{Grammatical Pattern}

\section{Subject Omitting}

Firstly, we focus on the omitting subject feature. Hagrid frequently leaves his sentences with no subject though it does not always happen.

- "Borrowed it, Professor Dumbledore, sir," (14)

- "Nah — can’t spell it." (54)

The subject of ' $\mathrm{I}$ ' is omitted from the sentences as Hagrid is confident enough that the hearer understands the meaning. Although the subject is omitted by Hagrid, the whole dialogs still give a clear clue of whom or what Hagrid is talking about. However, the most significant subject omitting is invested when the subject is Hagrid himself.

\section{Pronoun Changing}

Another prominent feature attributed to West Country dialect is the exchange of the pronoun. Marshall (1789) has pointed out that a variant changing of pronoun exists in the dialect. It also appears in Hagrid's utterances as shown below:

- “True, I haven't introduced meself." (48)

- "Shouldn'ta lost me temper," (59)

The sentences should contain 'myself' and 'me' instead. Here, the dialect changes the pronoun. 


\section{Auxiliary Verb Omitting}

Auxiliary verb does not have an exact meaning in a sentence. However, it holds an important role that makes a sentence complete and grammatically correct. Another feature of the dialect in Hagrid's utterances is the absence of auxiliary verb as shown below:

- 'Harry Potter not knowin' his own story when every kid in our world knows hisname!" (53)

- "I bin waitin' fer half an hour already." (249)

\section{Auxiliary Verb Modification}

As it has been revealed about a unique word of 'bin' in the dialog of previous point, the auxiliary verb has been modified to a form which is familiar to Hagrid. The dialogs contain 'bin' are shown below:

- “Bin watchin' from me hut," (187)

- “Well, I've bin doin' some readin',"(233)

\section{Double Negation}

One negation is enough to show a negative form of a sentence. Therefore, two negations or more in one sentence are known as a vernacular form of language which indicates a dialectal feature. Hagrid also shows more than one negation in his utterance like below:

- “That wasn' no werewolf an' it wasn' no unicorn, neither," (252)

Despite the fact that Hagrid uses more than one negation, the sentence's meaning remains negative.

\subsubsection{Vocabulary Variation}

The distinction of pairs of words shows the distinction of the social group a person belongs to. It is also a matter of word choice. Hagrid uses unique words in his sentences. Here is the table of Hagrid's vocabulary variation.

Table 3 Hagrid's Vocabulary Variation

\begin{tabular}{ccc}
\hline $\begin{array}{c}\text { Vocabulary } \\
\text { Variation }\end{array}$ & Literal Meaning & Used to Show \\
\hline Gallopin' Gorgons & Fast-running & Surprise \\
Gulpin' gargoyles & monsters & Surprise \\
Blimey & Swallow a big stone & Surprise \\
Codswallop & figure & Disbelief \\
Crikey & God, blind me & Surprise \\
Rabbitin' & Nonsense & Impatience \\
& - & \\
& Talk at length, & \\
& especially about & \\
& trivial matters & \\
\hline
\end{tabular}




\subsection{Significance of the dialect toward Hagrid's Characteristics}

The dialect owned by Hagrid is an English dialect as one of the sentences uttered by Hagrid shows a significant proof that it is a dialect from the land of England. Specifically, other sentences are studied in other to know the particular dialect. In the use of 'yeh' instead of 'you', it shows the similarity with 'ye' in West Country dialect. As stated in British Library Official Website, 'ye' is a very traditional feature of West Country dialect. It is used to express the second person pronoun. The history of 'ye' comes from the forms of 'thou', 'thee', 'you' and 'ye' changing for different functions at different times and different parts of the UK. The use of 'ye' or 'yeh' still can be encountered among older speakers and nowadays usually in question forms or in commands. However, the function of the words varies from place to place.

It is strengthened by Rowling's statement that dialect used by Hagrid is West Country one. Rowling was interviewed in March 2001 in BBC Radio. When she asked about Hagrid's language variation, she answered that it belongs to the West Country where she comes from.

From the analysis above, the dialect used by a character in a novel is able to be analyzed. Not only from the particular place where the dialect comes from, but also the pattern of the dialect and the social group which it represents. Moreover, the result of this research will give a new nuance of dialect analyses which are mostly done in real society. This research will give contribution to English dialect analysis and enrich the finding of one particular dialect's pattern.

Hagrid was raised in an area which was surrounded by one distinctive dialect, which is West Country, and it embosses to his speech routine and gives him a signature characteristic. Among other characters in the novels, the way J.K. Rowling types Hagrid's way of speech is quite unique as the dialogs show the West Country dialect.

The use of vernacular form of a language may represent the background of the user. Like the [h] dropping, other consonant dropping also represents a lower social group. Also, -ing ending pronunciation describes that the person who produces the utterance represents to the lower social group. By this, it reflects that Hagrid represents a lower social group. It is in accordance with the story which puts Hagrid as the Gatekeeper of Hogwarts. Usually, security or guard is considered to have a lower educational or professional background than other staffs in an institution, so as Hagrid.

Also, the use of vernacular grammar like omitting the subject of the sentence shows a significant represent of the lower social group. This is due to the lack of necessity in using the standard grammar. The lower social group tends to rely on the listener to predict the subject of 
the conversation. It means that people in the lower social group do not care too much about the completeness of the sentence. They tend to be more concerned in the delivering of the message itself.

From the choice of words owned by Hagrid, it also reflects that he represents the lower social class. Both "Gallopin' Gorgons" and "Blimey", words he uses when he is surprised, are rarely used by the professors or other staffs in Hogwarts School. Only few students use "Blimey" to express their surprise. It again concludes that Hagrid represents lower social group where mostly the members of the group are known as laid-back persona. They tend to ignore the standard rule and choose their own vocabulary to express their feelings as there are few demands of using standard language.

Rowling gives West Country dialect to Hagrid. The writer tries to reveal the reason why she gives the dialect from the place she was born to him, not to other character. It is supposedly because Hagrid is a very bright character. He, though experiences bad things through his life, always believes in goodness and maintains friendship. He is always loyal to Dumbledore and Harry and always tries to do his best. Those good things of Hagrid make Rowling feels it is suitable for her to attribute him with the dialect from where she comes from. She gives the dialect to Hagrid to make an implicit description that people from West Country are very simple and humble. She wants to emphasize that, though Hagrid is a peripheral character and often considered as less educated than the others, he still holds a very important role in the novel. Also, it seems that she wants to describe that, disregarding the physical appearance and the way to speak, what matters is one's heart and personality.

\section{CONCLUSION}

The patterns of Hagrid's dialect vary from the range of phonology feature, grammatical pattern, and vocabulary variation. From the phonology feature, there are consonant droppings, which omits the pronunciation of a consonant. Hagrid only drops the $[\mathrm{t}]$, [d], and $[\mathrm{v}]$. By creating this unique typing, Rowling invites the readers to create imagination about how Hagrid is supposed to speak which is by dropping the consonants. He also pronounces -in instead of -ing and contracts some words in his utterances. In addition, he pronounces some function words differently as 'ter', 'yeh', 'yer', and 'fer' instead of 'to', 'you', 'your', and 'for' respectively. From the grammatical pattern, there is subject omitting,pronoun changing, auxiliary verb omitting, auxiliary verb modification, and double negation. From the vocabulary variation, there are the usages of words which are spontaneously uttered by him. Although Hagrid shows inconsistency in his speech style by juxtaposing the dialectical 
features and the standard forms of language, the dialectical pattern still mostly appears on his utterances.

Based on the analysis of the whole dialectical features, Hagrid represents the lower social group. However, Rowling attributes the dialect to Hagrid for some reasons. She wants to preserve her hometown dialect into a bright and loyal character. Hagrid is described in the book as a nice character with warm personality. Thus, Rowling gives the dialect to make an implicit description that people from West Country are very simple and humble.

\section{REFERENCES}

A'la, A. (2009). An Analysis of Jamaican Dialect Used on Bob Marley Songs. (Unpublished undergraduate thesis, The State Islamic University of Malang).

Blimey. (n.d.). Urban Dictionary. Retrieved 19 May 2014 from http://www.urbandictionary.com/define.php?term=blimey

British Library. (2013). Melksham. Retrieved 19 May 2013 from http://www.bl.uk/learning/langlit/sounds/text-only/england/melksham/

British Library. (2013). Portesham. Retrieved 19 May 2013 from http://www.bl.uk/learning/langlit/sounds/text-only/england/portesham/

Bucholtz, M., Bermudez, N. Fung, V. Edwards, L. \& Vargas, R. (2007). Hella Nor Cal or Totally So Cal?: The Perceptual Dialectology of California. Journal on Linguistics. Sage Publication: http://www.sagepublications.com

Burchfield, R (Ed). (1994). The Cambridge History of the English Language. Cambridge: Cambridge University Press.

Dialect Blog. (2014). British Accents. Retrieved 6 March 2014 from http://www.dialectblog.com/british-accents/

Gorgons. (n.d.). Oxford Dictionaries. $\quad$ Retrieved 26 May 2014 from http://www.oxforddictionaries.com/

Holmes, J. (1992). An Introduction to Sociolinguistics. New York: Longman Publishing

Wardhaugh, R. (1977). Introduction to Linguistics. Bloomington: Indiana University Press. 